\title{
The concise argument
}

doi:10.1136/jme.2010.036681

Søren Holm, editor

\section{Translational ethics}

Alan Cribb is one of my favourite medical ethicists, not only because I count him as one of my friends, but primarily because he writes wonderfully nuanced and insightful papers.

In this issue we are pleased to publish a paper by Alan asking whether there is a theory-practice gap in medical ethics, and, if so, how best to bridge it (see page 207). Does medical ethics need a 'translational ethics' movement along the lines of the translational medicine movement that tries to bridge the research-therapy gap?

Alan argues that there is a theorypractice gap in medical ethics, but that such a gap is probably inevitable for, as he notes: 'Doing scholarship is doing something different from policy or practice'. And scholarship and policy-making have different ends, goals and objectives.

We could attempt to bridge this gap through an 'Enlightenment model' where medical ethics informs policy-making in different ways, but this model has its own problems. If medical ethics is only part of the 'How' of policy-making, there will be circumstances where the outcome of the process is ethically unacceptable, despite the input from medical ethics. And the ethics expert will be forced back to explicitly state the 'What', that is that some policies are acceptable and others are not.

Where does this leave us? Alan Cribb suggests that we need a much more indepth and explicit discussion of the relationship between ideal and non-ideal theory in medical ethics. I think he might be right!

\section{Trust in researchers}

It is a commonplace in discussions of research ethics that research participants need to be able to trust researchers and that potential research participants are more likely to consent to participation if they have trust in the person asking them to participate. But trust is a multi-faceted concept, and just stating a requirement of trust is therefore not very enlightening. The study by Woodgate and Edwards exploring the link between risk assessment and trust in research with children adds very significantly to our knowledge in this area (see page 211). The authors used interview and focus group methodologies to study the views of parents and children about their views and experiences of participating in clinical research.

Their results show that there is a complex interplay between risk assessment and trust, and that many different kinds of trust are involved in the research process. Some of these types of trust are engendered in relations, whereas others are trust in symbols or institutions. They furthermore found that trust is dynamic. Its magnitude and character changes and fluctuates over time.

\section{Research ethics committees-a farewell to 'orientalism'?}

There may well in the past have been an 'orientalist' strand in the perception of us Westerners about research ethics committees in non-Western countries. Research ethics committees were our invention and could not possibly be implemented as well in countries without our democratic institutions.

The paper by Rwaibihama et al provides an important corrective to such ideas (see page 243 ). The paper provides an analysis of research ethics committees and systems in 20 African countries. It shows that the standard of research ethics at the national level is now high and continually improving. This development has been driven by the increasing involvement of Unesco, WHO and others in providing guidance and training for committees. Most countries now have research ethics committees at the national level that are well constituted, knowledgeable and independent.

On the basis of this analysis, the authors make the interesting observation that there might be scope for some Western countries to take another look at their own research ethics committees, especially with regard to independence. The targets for this criticism are those countries that allow institutional research ethics committees, since it is difficult to see how such a committee would not have considerable potential conflicts of interests.

\section{John Harris and Islamic bioethics} It may come as a surprise to many, including John Harris himself, but, in a paper in this issue, Sahin Aksoy shows that there are a number of areas of congruence between the ethics of John Harris and foundational principles of Islamic bioethics (see page 226). Aksoy argues that, in areas such as personal responsibility for action, the rejection of the doctrine of double effect, equality and justice, and blameless wrong-doing, Harris and the Prophet Muhammad are in basic concordance. Aksoy acknowledges that Harris and the Prophet quite frequently diverge in the specific, practical application of these basic principles, but he nevertheless sees a basic unity.

I will leave it to the readers to try to unravel any wirkungsgeschichte linking the Prophet and Harris or, conversely, to assess the chances of a profound Harrisian influence on future development in Islamic bioethics. 